\title{
Skills and employment under automation: Active adaptation at the local level
}

\author{
Odd Bjørn Ure ${ }^{\star 1}$ and Tom Skauge ${ }^{2}$ \\ ${ }^{1}$ Consultur. Studies \& Analyses, Westye Egebergs gate 2 B, Oslo, Norway \\ ${ }^{2}$ Western Norway University of Applied Sciences, Department of Business Administration, \\ Campus Kronstad, Bergen, Norway
}

Received: 16.02.2019, Accepted: 08.07.2019, Published: 19.12.2019

\begin{abstract}
Context: The article contributes to a discussion of how patterns of employment and qualifications are modified by the ongoing industrial transformation, called Industry 4.0. Although this transformation is said to be a global phenomenon, scholars increasingly discuss the national differences in the wake of Industry 4.0. Our article aims to intervene in this debate by analysing the industrial transformation of a small island situated at the West coast of Norway. We notably investigate the technological renewal by means of Computerised Numeric Control (CNC) and robotics in a network of mechanical firms.

Approach: Nine small mechanical engineering firms are analysed by drawing on theories on business networks and clustering of firms. This allows for a discussion of how automation, employment, staff training and profitability are interconnected. The main research question is how the firms are locally embedded in a way that sheds light on the social dimension of vocational training, which is considered a form of Corporate Social Responsibility.

Findings: It is informative to use the heuristic concept 'pre-cluster agglomeration' to characterise how the nine firms under scrutiny are interacting, while being assisted by a forwardlooking industrial association and supported by an active local community. The municipality and the county to which this agglomeration belongs, provide training services and other infrastructures that support the firms when they recruit new employees and upskill their staff, - notably by setting up a CNC training centre attached to an upper secondary school.
\end{abstract}

* Corresponding author: oddbure@gmail.com 
Conclusion: Our case does not support off-the-shelf narratives of robotisation implies job cuts. In the same way as previous technological transformations were not solely driven by their inherent technical opportunities, the ongoing robotisation is nuanced by the social shaping of technology. There is room for strategic choices when new technology is integrated in work organisations. The extent to which the workforce should be (re-)trained is subject to decisions and negotiations.

Keywords: Case study, technological change, workplace change, employment pattern, labour utilisation, job skills, training activities, vocational education and training, VET

\section{Introduction}

\subsection{Robotisation, skills and employment}

Robotisation may be interpreted as a paradigmatic shift from broad data-technological platforms to smart, adaptable production (Schwab, 2016). It is customary to calculate the potential of Computerised Numeric Control (CNC) and robotics (in short: automation) under the headings of mass production, punctuality and quality (Alvares, 2007; Åström, 2004).

It is often claimed that robotisation, as part of the ongoing transformations called Industry 4.0, inevitably leads to less demand for human labour. Some scholars maintain that robotics could engender productivity gains in situations where factories are losing most of their workers (Brynjolfsson et al., 2014; Acemoglu \& Restrepo, 2017). This could be a daunting prospect for communities dependent on low-diversified industries exposed to the immediate effects of robotisation, notably the automation of repetitive, mechanical operations.

One of the most influential scenarios of drastic job cuts is found in Frey \& Osborne (2013) who distinguish between high-, medium- and low-risk occupations according to their exposure to computerisation. They estimate that 47 percent of total employment in the United States is in the high-risk category, meaning that the occupations concerned are potentially automatable, "perhaps (over) a decade or two" (ibid, p. 41). In a discussion of Frey \& Osborne's arguments as applied to Germany, Bonin et al. (2015) maintain that new machinery has the potential to change the workplace without replacing the actual place of work. Hence, employees who are automated away from repetitive tasks could instead carry out operations less exposed to automation. In the same vein, D. Rus (2015) pinpoints that product innovations can partly counteract staff redundancy during automation and robotisation.

Moreover, Helmrich et al. (2016) point out that the studies on which Frey \& Osborne (2013) build their arguments are based on the North-American or United Kingdom labour markets which have fewer workers in the medium-risk occupations claimed to be most exposed to automation. Helmrich et al. note that labour markets in several European countries are 
more heterogeneous in the sense that there is a high proportion of medium-skilled workers who are supported by institutionalised arrangements for vocational and educational training. This is supported by S. Pfeiffer (2015) who argues that training in broad vocational skills providing access to a wide array of occupations, including medium-skilled jobs, renders the workers more robust when confronted with the technological renewal of their workplaces.

Another criticism of Frey \& Osborne (2013) is that their investigation of the technical potential tends to ignore societal, legal and ethical obstacles to the introduction of new technologies (Bonin et al., 2015). This important approach acknowledges the potential for active adaptation at the local level through public discourse. One example is found in Germany where - from 2011 and onwards - a constellation of business and science interests was enlarged to include trade unions at the same time as the government altered the paradigmatic label 'Industry 4.0' to 'Work 4.0' (Ahrens \& Gessler, 2018).

Our article addresses some links between automation, occupational transformation and employment patterns (job losses and job creation) by analysing a specific, local community. Our main hypothesis is that the incremental introduction of robots, combined with upskilling in a context of mutual trust, has facilitated these manufacturing transformations. The article focuses on the local conditions affecting this transformation. We thereby thematise the social dimension of vocational and educational training (Kaiser \& Krugmann, 2018) which covers individual and collective or institutional activities, including cooperation between groups of persons or institutions (ibid.). Kaiser \& Krugmann argue that the predominance of a relationship of trust and reliance within society is fundamental for developing "a social and participatory attitude towards the new and the foreign". This is a perspective for the whole society, conveyed across various levels, of which the text below concentrates on a local level.

\subsection{Theoretical and methodological foundations}

The article starts with the literature on business networks and clusters, focusing on how the networks and clusters are embedded in local communities. These theoretical strands are supplemented by literature with a vocational perspective on technological renewal, particularly robotisation. A third theoretical source is contributions that shed light on the social dimension of vocational education and training (VET) and which have some affinity with the literature on Corporate Social Responsibility (CSR).

Methodologically, the article builds on case studies of nine firms, of which the three most robotised ones are scrutinised in depth. In addition to interviews and the examination of written material on the firms, the case studies are supported by a value index to measure enterprises' economic sustainability. The article addresses the limitations of our findings from one single local community by drawing on literature with a national and transnational bearing. 


\section{Collaborative training in Business network and clusters: Theoretical perspectives and previous studies}

An investigation of automation and robotisation of industrial communities needs to capture relationships between the local firms as well as how these firms individually and collectively interact with the environment. One strand of the study of business networks looks at the activities, resources and actors that are in play in these networks. Broadly speaking, the network actors interact either individually towards their 'small world' or collectively towards the 'large world' (Håkansson et al. 2009). Theories on industrial communities of a different nature can shed light on which local or regional actors are involved in the various networks supporting a firm. One theoretical discussion is whether a distinction should be made between industrial districts, networks and clusters. Another is how clusters can be distinguished from (local or regional) networks (Bathelt et al., 2004; Fløysand et al., 2012). In practice, however, these notions may refer to very similar organisational constellations (Ure \& Skauge, 2014).

The empirical material for the present article concentrates on nine enterprises and a local industrial association, the Osterøy Manufacturing Industry Association, which among other things represents them in contact with municipal and regional authorities. The association covers 40 firms situated around Osterfjorden. The activities of this local business network are therefore characterised by a manufacturing association able to unify the interests of individual firms but these individual firms rarely cooperate directly to increase their added value. Instead of regarding this association as a network external to the firms, it can be determined as an extension of them (ibid.). Furthermore, an understanding of how the firms interact as a business network increasingly exposed to competition and robotisation could cast light on whether they constitute one fragment of a larger industrial district or of a cluster. The terms cluster and industrial district are older terms in economic theory, dating back to Alfred Marshall's 'The Principles of Economics' (1890).

In the industrial association we are studying, the external relations of the firms seem more determined by local society and the municipality than by business relations in the strict sense as outlined in analyses inspired by Michael Porter. The latter primarily aim to determine the competitiveness of industrial agglomerations (Porter, 1980 and 2014; Reve \& Sasson, 2012), while the business network of the enterprises now under scrutiny have very close relations to their local environments (Njøs \& Jakobsen, 2016). This environment embraces civil society, associations of employers, labour unions, education institutions and other providers of training alongside technology suppliers and cooperative bodies at the local level such as industrial associations or similar bodies of importance in the district. Previous studies of the industrial agglomeration under scrutiny have confirmed the determining feature of the local community surrounding the member firms of the Osterøy Manufacturing Industry Association (Lindeløv 2014; Skjærvik, 2014). 
The organisational aspects of a firm, both internally between staff categories or professions and externally towards the firm's environment, raise the question as to how vocational qualifications can be studied. In an article on formal and integrated strategies for competence development in small firms, Kock \& Ellström (2011) suggest that organisational and technological innovations are intertwined. Alice Lam (2006) explicitly shares this view by claiming that collective knowledge is the accumulated knowledge of the organisation stored in its rules, procedures, routines and shared norms. This knowledge guides the problem-solving activities and frames the patterns of interaction among members of the organisation. Furthermore, differences in organisational interpretations of and responses to external stimuli can affect the outcomes of organisational change (ibid.).

Our chosen perspective builds on the theorising of the institutional aspects of innovation (Peng et al., 2009) and the social dimension of vocational training. We investigate how the local community surrounding the group of enterprises is involved when CNC and robotics transform manufacturing processes and the enterprises' organisational framework. One example is the mobilisation to set up a training centre at the local upper secondary school in order to support the automation and robotisation of the neighbouring mechanical industries. This form of mobilisation is often pivotal for supporting the capacity of the firms to embark on local adaptations and technological renewal (Fløysand et al., 2012). We assume that investments in automation technology and the competencies needed when choosing the most suitable technical installations, as well as how to implement the technology in an inter-firm environment, lay the foundation for innovations at the level of the firm. Our material suggests that this happens in a form of 'stakeholder dialogue', which can be broken into the voluntary Corporate Social Responsibility (Carson et al., 2015) exercised by enterprises when confronted with the weighting of job creation vs. job cuts during introduction of CNC and robotics. This weighting underpins the value index displayed in table 2 below (Laurantsen \& Bergfjord, 2014).

Studies of similar clusters or pre-cluster agglomerations have also emphasised the importance of having a local labour market characterised by trust between firms, including a reduced fear that an employee trained by one enterprise would leave to work at another ('poaching'). This coincides with the general findings of Norwegian training patterns and is further explained by low staff turnover and by observations that most of the employees are highly integrated in local communities. This integration contributes to the formation of a quite stable workforce (Ure, 2010). Such characteristics also apply to the pre-cluster agglomeration around Osterfjorden. 
The considerations above pave the way for our three research questions:

1. What are the main drivers behind the local shaping of employment patterns in a network of mechanical engineering firms?

2. In local enterprise networks, how are decisions on profitability, investment in technology and automation, and staff recruitment versus layoffs conciliated or weighted against each other? Are there signs that the social dimension of vocational training is manifested through social responsibility and the emergence of specific training cultures?

3. Faced with the widespread apprehension that robotisation implies job cuts, do employers take this into account by implementing a form of Corporate Social Responsibility (CSR) that tackles concerns about keeping staff on during robotisation and provides opportunities for further and continuing training?

We will revert to these questions in the concluding section. Before that, the local community and its mechanical firms are analysed. Then the findings will be discussed and related to the strands of literature presented above.

\subsection{The local community: mechanical engineering firms investing in new technology}

Small and medium-sized mechanical enterprises (SMEs) in the county of Hordaland on the west coast of Norway survived high production and wage costs during an upswing in the petroleum and oil services industries which ended when oil prices plummeted in 2014. During the preceding years, small firms' survival often rested on a strategy of gradually introducing Computerised Numeric Control (CNC) machines and later robots. The firms belonging to the network that we investigated introduced robots in a smooth prolongation of their CNC investments. This illustrates a gradual transition between Industry 3.0. and Industry 4.0., whereby typical 4.0-technologies like recognition of images and voices, alongside the storage of data for reuse in the next manufacturing series, are being gradually introduced on the shop floor.

Computerised Numeric Control is a technology with considerable managerial and organisational impact at the level of the firm (Marri et al., 1998). It is usually based on ISO standards and was rapidly disseminated in most branches of industrial production (Martin \& Beach, 1992). CNC preceded in many ways robotics because industrial robots are controlled with similar technology. Industrial robots are becoming more and more affordable. They are highly attractive for small and medium-sized enterprises with modest production volumes and differentiated production lines. 
For a group of small firms in a district around the Osterfjord, investment in CNC and robotics entails innovation that makes room for new products and more knowledge-based jobs (Skjærvik, 2014). These firms are working in the field of mechanical engineering. Their manufacturing process has evolved from simple products destined for local customers to a portfolio of technologically-advanced products delivered to national and international customers. Some forward-looking firms around the Osterford started more than 20 years ago to invest in CAD/CAM programmes, CNC machines and later also robots (ibid.).

In 2010, the county administration in Hordaland joined forces with local industries to set up a 'Competence centre for CNC and robotics' at Osterøy upper secondary school. Before the training centre appeared, the industrial association cooperated with the upper secondary school in order to support its vocational programmes, particularly those of relevance for local industries. The centre now consists of $10 \mathrm{CNC}$ training stations and two robots. A majority of those trained at the centre are enrolled in apprenticeship training, while there are plans to expand the educational offer to allow more employees from local enterprises to attend further and continuing training. The training centre is active in crafting a local, hightech, industrial culture' including a vocational programme for apprentices called 'Technique and Industrial Production (TIP)' at upper secondary level (Gjelstad, 2015). The Osterøy Manufacturing Industry Association has approximately 40 members whose general manager is partly financed by the municipality. The association has a central role in discussing joint projects among its members and, for example, proposing to public authorities the setting up of training at the local CNC centre, as well as being a go-between in discussions with funding bodies, for example Innovation Norway (Lindeløv, 2004).

\subsection{Automation and robotisation shape a municipality}

Among the 40 member firms of the Osterøy Manufacturing Industry Association, 15 are classified as manufacturing entities. Within this selection, we had enough information about nine firms to allow us to investigate their economic sustainability and employment patterns (see tables 1 and 2 below). The nine selected firms also constitute a sample with fairly similar production processes and production lines.

All these firms are to be found on the island of Osterøy, which constitutes a municipality in the vicinity of Bergen, Norway's second largest city. This rural municipality has some 8,000 residents. Its enterprises feel constrained by a deficient road system which over the years has hampered easy access to Osterøy itself as well as hindering transport across the island. Osterøy today is about to become a robotised municipality due to the local industry's investment in new technology. The introduction of $\mathrm{CNC}$ and robotics adapted to small and medium-sized enterprises was a key innovation strategy for the mechanical engineering industry around the Osterfjord, which expanse of water separates the island from adjacent municipa- 
lities. Moreover, three small neighbouring municipalities have joined together in the Osterfjord Industry Collaboration with a view to coordinating the administrative and counselling services for enterprises in the municipalities. For this purpose, a partnership agreement with the relevant county authorities has been signed, thus demonstrating the intertwinement of business and public interests that frames the working conditions of this group of small firms.

\subsection{Profitability, staff numbers and robotisation in the nine firms}

The overview in table 1 below shows that several firms display consistently solid results over the decade in question (2006-2015). These firms are Lonevåg Fittings Factory, Gunnebo Anja Industries and Jon Solberg Fittings Factory. Two other firms, K. Lerøy Metal Working and Jakta Metal Working, experienced quite low profits, as did Tysse Mechanical Engineering in the aftermath of the 2008 global financial crisis. Yet the latter firm had very good results before this crisis but after 2009, the value creation of Tysse Mechanical Engineering plummeted.

The value index compares profitability and book equity (Laurantsen \& Bergfjord, 2014). The index is composed so that a firm cannot be considered economically sustainable if it over several consecutive years scores below $100 \%$. This means that if the value of a firm's equity capital is not higher than the original capital, its economic sustainability is at stake. The nonweighted average for all enterprises indexed in table 1 is some $238 \%$. This suggests that they yield well for the owners, meaning that they are economic sustainable. Yet, during some years some enterprises score below 100 \% (Bergfjord og Laurantsen, 2014).

Table 1: Value index of the nine enterprises' economic sustainability, 2006-2015

\begin{tabular}{|c|c|c|c|c|c|c|c|c|c|c|}
\hline Firms/Year & 2006 & 2007 & 2008 & 2009 & 2010 & 2011 & 2012 & 2013 & 2014 & 2015 \\
\hline TYSSE MECHANICAL ENGINEERING & $+13 \%$ & $329 \%$ & $224 \%$ & $211 \%$ & $128 \%$ & $99 \%$ & $38 \%$ & $7 \%$ & $0 \%$ & $0 \%$ \\
\hline ONEVÅG FITTINGS FACTORY & $114 \%$ & $101 \%$ & $101 \%$ & $103 \%$ & $110 \%$ & $118 \%$ & $123 \%$ & $133 \%$ & $126 \%$ & $114 \%$ \\
\hline GUNNEBO ANJA INDUSTR & $231 \%$ & $309 \%$ & $1029 \%$ & $1375 \%$ & $250 \%$ & $144 \%$ & $92 \%$ & $134 \%$ & $226 \%$ & $342 \%$ \\
\hline MJØS METAL WORKING & $211 \%$ & $183 \%$ & $180 \%$ & $205 \%$ & $175 \%$ & $154 \%$ & $119 \%$ & $102 \%$ & $78 \%$ & $75 \%$ \\
\hline K. LERØY META & $180 \%$ & $216 \%$ & $443 \%$ & & $323 \%$ & $3 \%$ & $0 \%$ & $0 \%$ & $0 \%$ & $0 \%$ \\
\hline JAKTA METAL WOR & $97 \%$ & $106 \%$ & $84 \%$ & $232 \%$ & $186 \%$ & $89 \%$ & $64 \%$ & $42 \%$ & $0 \%$ & $0 \%$ \\
\hline JON SOLBERG FITTINGS FACTORY & $136 \%$ & $397 \%$ & $371 \%$ & $391 \%$ & $376 \%$ & $332 \%$ & $285 \%$ & $267 \%$ & $281 \%$ & $375 \%$ \\
\hline FJELLSKÅLNES MECHANIC. ENGINEERING & $190 \%$ & $188 \%$ & $221 \%$ & $303 \%$ & $231 \%$ & $181 \%$ & $178 \%$ & $123 \%$ & $115 \%$ & $115 \%$ \\
\hline JEVLE MECHANICAL ENGINEERING & $0 \%$ & $105 \%$ & $139 \%$ & $246 \%$ & $212 \%$ & $140 \%$ & $165 \%$ & $169 \%$ & $159 \%$ & $157 \%$ \\
\hline
\end{tabular}

Table 2 below shows that the number of employees in the selected nine enterprises has been quite stable over the years 2006-2015. One exception is Jakta Metal Working, which went bankrupt in 2016, i.e. one year after our reference period (cf. Proff Forvalt). 
Table 2: Number of employees in the nine enterprises, 2006-2015

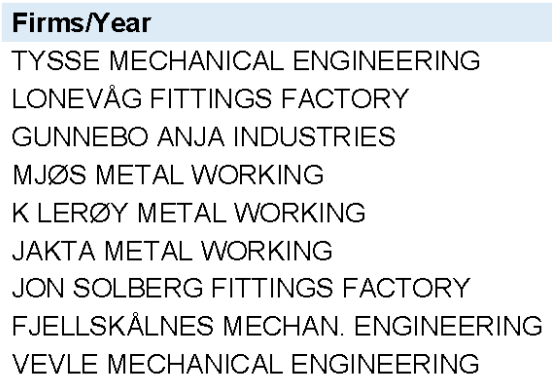

$\begin{array}{rrrrrrrrrr}2006 & 2007 & 2008 & 2009 & \mathbf{2 0 1 0} & \mathbf{2 0 1 1} & \mathbf{2 0 1 2} & \mathbf{2 0 1 3} & \mathbf{2 0 1 4} & \mathbf{2 0 1 5} \\ 55 & & 70 & & 81 & 80 & 85 & & 81 & 81 \\ 54 & 58 & 53 & 53 & 55 & 55 & 55 & 58 & 58 & 62 \\ & 127 & 127 & 96 & 51 & 54 & 55 & 56 & 59 & 54 \\ 42 & 45 & 45 & 45 & 48 & 49 & 52 & 55 & 55 & 55 \\ & 36 & 45 & 35 & 37 & 37 & 39 & 39 & 36 & 36 \\ & & 22 & 21 & 16 & 28 & 23 & 23 & 23 & 23 \\ 16 & 17 & 15 & 13 & 12 & 11 & 10 & 10 & 11 & 10 \\ 13 & 13 & 13 & 13 & 13 & 9 & 9 & 9 & 8 & 8 \\ 4 & 4 & 4 & 4 & 4 & 4 & 5 & 5 & 6 & 6\end{array}$

The next table, Table 3, shows how many robots the enterprises have installed compared to the number of employees. Most of the nine firms have introduced robots but the use of them varies between the firms. Note that other automation technology, like CNC, is not included in the table.

Table 3: Robot density in the nine enterprises, 2015-2016

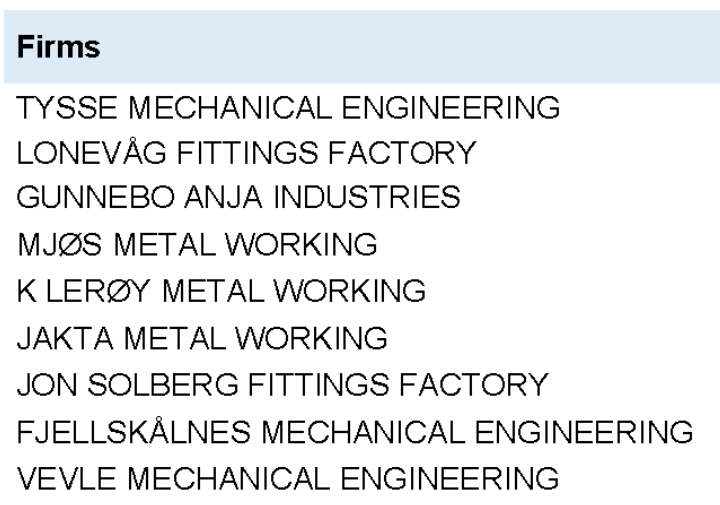

$\begin{aligned} & \text { Robots } \\
& \text { 2016 }\end{aligned}$
\begin{tabular}{|r|r|r|}
\multicolumn{1}{l}{$\begin{array}{l}\text { Employees } \\
\text { 2015 }\end{array}$} & $\begin{array}{l}\text { Robots/ } \\
\text { employees }\end{array}$ \\
\hline $5+5$ & 81 & $12,4 \%$ \\
\hline 50 & 62 & $80,7 \%$ \\
\hline 4 & 54 & $7,4 \%$ \\
\hline 4 & 55 & $7,3 \%$ \\
\hline 3 & 36 & $8,3 \%$ \\
\hline 3 & 23 & $13,0 \%$ \\
\hline 0 & 10 & $0,0 \%$ \\
\hline 1 & 8 & $12,5 \%$ \\
\hline 0 & 6 & $0,0 \%$ \\
\hline
\end{tabular}

(Source: Osterøy Manufacturing Industry Association, data obtained in October, 2016).

As shown in Table 3, Lonevåg Fittings Factory has invested heavily in robots, to the extent that this form of automation is fundamental to the firm's manufacturing process. The large wafer-production bending centre at Tysse Mechanical Engineering roughly corresponds to five robots in a $5+5$ constellation. A third firm we investigated, Mjøs Metal Working, has bought four robots for the manufacturing of their wide range of mechanical products. We will concentrate our further analysis on these three firms, partly because they are the most automated or robotised among the larger population of nine. In addition, the quality of the 
collected material from these three firms, which have been frequently visited as part of a cooperation agreement between the industrial association and a university college, allows us to draw on supplementary information related to our research questions.

\section{Timelines for technology investments in the three mechanical enterprises}

The following text is based on a timeline of the three mechanical enterprises' investments in technology as first elaborated in Skjærvik (2014).

\subsection{Tysse Mechanical Engineering Ltd.}

Tysse Mechanical Engineering produces automotive trailers and started its technological renewal in 1994. The firm then boosted the development of machinery and output in sheet metal forming. A large contract from the Norwegian Army increased the overall production volume. Whereas it was deemed more expensive to buy sub-products from outside suppliers, the firm decided to manufacture the needed sub-products on its own. The first purchase was a stamping machine. The ensuing investments in automation focused on process as well as product development. Our interviews revealed that it was not originally planned to introduce fully-automated production. There were two reasons for this: a fear of drastic job cuts and the unwanted side-effects of having too many types of trailers if a fully-automated plant were to be set up. In addition, the firm feared that its production volumes were too small to allow for full automation.

With these considerations in mind, Tysse Mechanical Engineering extended in 1996 its production facilities and developed a new, upgraded range of models. With plans to introduce a more modern production line, the firm purchased an automated stamping machine. In 2005, the annual production of automotive trailers reached 10,000, thus allowing the firm to obtain several ISO certifications. In 2012, Tysse acquired a new production line where the automated punching machine, a bending machine and the robotics centre were integrated.

The timeline in Fig. 1 below shows that the firm has gradually implemented new technology over the last 20 years. 


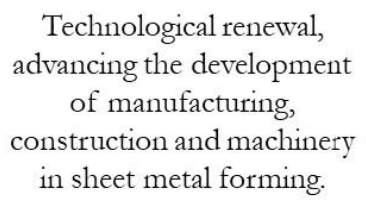

Technological renewal, advancing the development of manufacturing, construction and machinery in sheet metal forming.
New automated punch press - implementing a modern production line

\author{
ISO certified \\ NS-EN ISO 9001-2008 and \\ NS-EN ISO 14001-2008 \\ (environmentally certified)
}

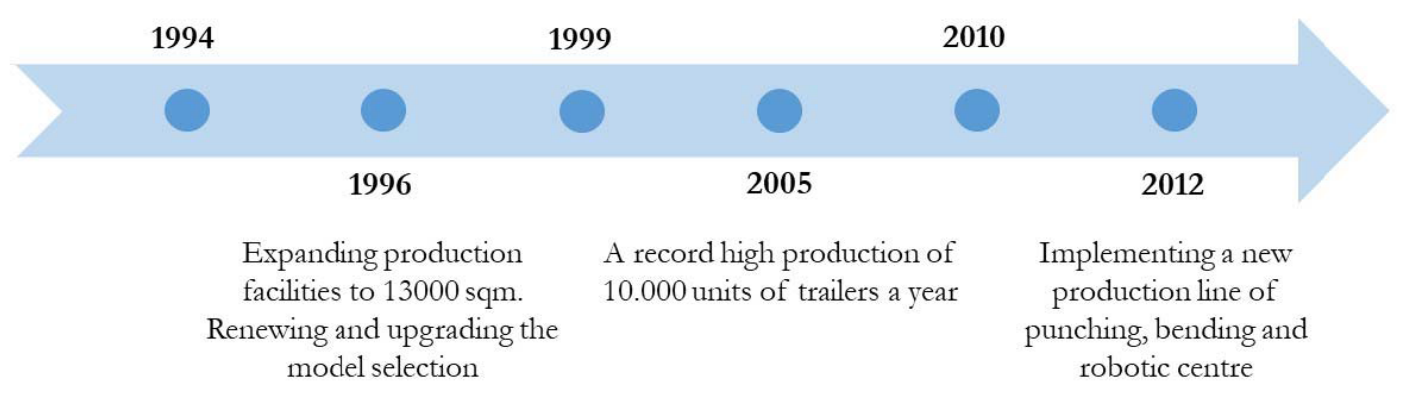

Fig. 1: Automation timeline of Tysse Mechanical Engineering Ltd. (1994-2012)

(Source: Skjoervik, 2014)

\subsection{Lonevåg Fittings Factory Ltd.}

Lonevåg Fittings Factory (Lobas) delivers rooftop safety equipment as well as equipment for gutters and garage doors. Production also includes roof guarding. Automation in Lobas started in 1999 when the firm invested in its first welding robot. The next step was an eccentric press of 200 tonnes and, in 2004, new roll forms and one eccentric press of 400 tonnes. In order to automate more parts of the production line, Lobas implemented a $2 \mathrm{D}$ vision system in 2006. This system helps robots identify various parts and carry out the appropriate operations. The production line was further developed in 2010 when the eccentric presses were integrated with robots. In 2012, Lobas introduced a process to use magnets for picking parts from pallets. The following year, an industrial conveyor belt removed the manual suspension of roof structures bound for powder coating. The firm's technological investments are illustrated in fig. 2 below. 


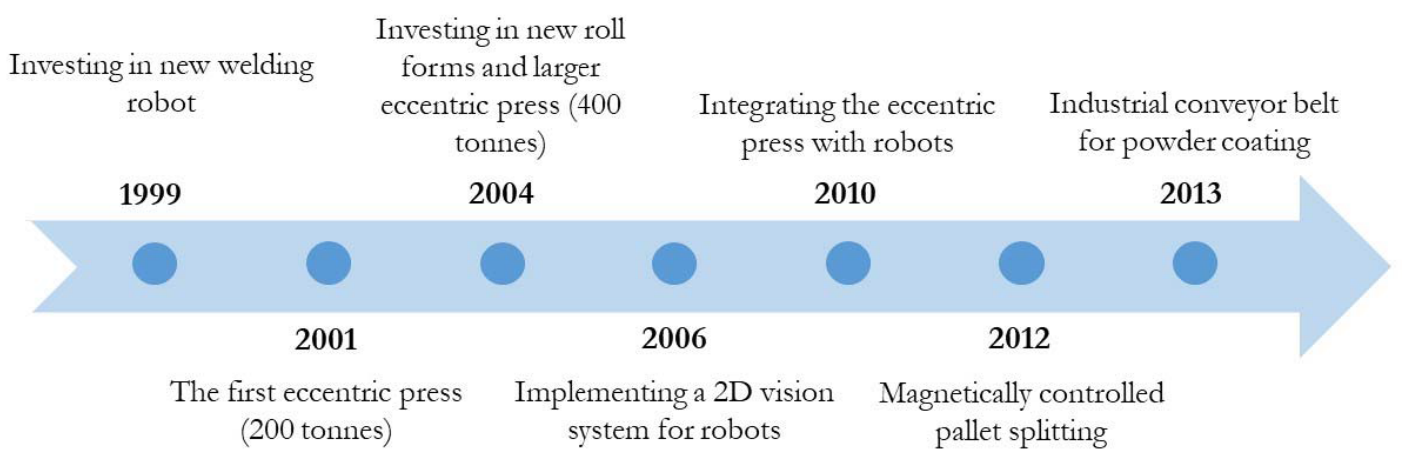

Fig. 2: Automation timeline of Lonevåg Fittings Factory Ltd. (1999-2013)

(Source: Skjorvik, 2014)

\subsection{Mjøs Metal Working Ltd.}

The technological upgrading of this firm has been rooted in its strategy to supply costumers with a wide range of mechanical products and services, from the development phase through prototyping and testing to production optimisation and delivery of pre-assembled and documented products. The firm accelerated its technological renewal in 1981 when a first lathe was installed. In 1986, its first CNC machining centre was put in place and, gradually, CAD/ CAM for producing programmes for CNC machines became customary. The firm bought its first lathe centre in 1995, followed by a Flexible Manufacturing Cell in 2001. The following year a Coordinate Measuring Machine was installed to verify that the manufactured parts comply with the required specifications. The first lathe and milling centre with robots was purchased in 2004 and, two years later, the firm acquired a five-axis machining centre. In 2013, a vertical lathe centre was integrated in the manufacturing process. Mjøs Metal Working is now certified according to ISO 9001:2008.

The timeline in Fig. 3 below shows that Mjøs Metal Working has experienced a gradual technological renewal from 1981 and onwards. 


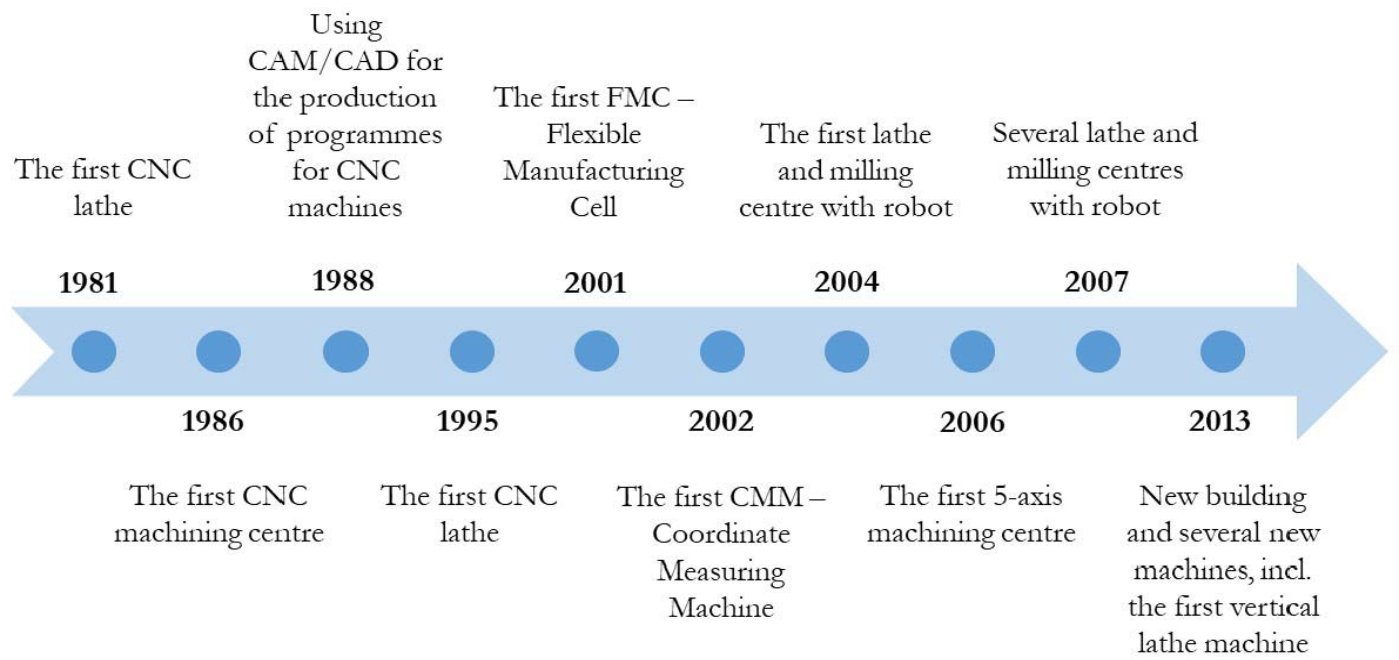

Fig. 3: Automation timeline of Mjøs Metal Working Ltd. (1981-2013)

(Source: Skjorvik, 2014)

\section{Summary and discussion of findings}

With one exception, the firms under scrutiny all survived and continued with a fairly stable workforce through periods of automation with $\mathrm{CNC}$ and robotics. The firm that most extensively utilises robots, Lonevåg Fittings Factory, has kept its workforce stable over the last ten years. During this period, the number of robots deployed in its manufacturing process increased from five to fifty. Similarly, between 2006 and 2016, the other firms that introduced automation technology did not reduce their number of employees. In some of the enterprises, the handling of new technology led to upskilling of the workers. A local Competence centre for $\mathrm{CNC}$ and Robotics has been used for training these workers. This training has allowed them to become more flexible when operating small-batch production for specific customers. Moreover, preliminary studies suggest that the workers concerned started to engage more actively in innovative adaptations of the production process (Gjelstad \& Skauge, 2009).

When analysing the three enterprises in more depth, we saw that some machine operators are autonomous in the first enterprise, operators mainly perform routine tasks in the second enterprise, while the third one has set up detailed descriptions of four different work roles for operators, of which one category is in charge of quite advanced 3D programming. The two first enterprises introduced new technology at a slow pace, while the third one has succeeded in a more wide-ranging utilisation of $\mathrm{CNC}$ and robotics. This success can partly be ascribed to a longer period of technology implementation. Two of the enterprises deliberately decentralised skills for handling new technology to the machine operators and, consequently, 
trained the operators to undertake new tasks. The third enterprise, however, decided to have a few specialists handling the robots while the majority of the operators performed routine tasks (Skjærvik, 2014).

These differences, observed among quite similar enterprises within the same municipality, suggest that there is room for strategic choices when new technology is integrated in work organisation. Skjærvik (2014) ascribes these variations mostly to deliberate decisions as to how to manage existing technological equipment and how to make new technology investments. In particular, a flat organisational structure with a bottom-up approach to managerial decisions seems pivotal for the successful and sustainable introduction of new technology in work organisations on the island under scrutiny (ibid.; Ure \& Skauge, 2014).

Other studies confirm that upskilling of operators strengthens the ability of inter-firm innovation which in turn increases the innovative performance towards customers. This is a central axiom in theories on 'Integrated Development Practices' such as that proposed by Price et al. (2012) who claim that contemporary workers expect to take responsibility and ownership for work activities not defined by their organisations or not bound to the jobs they were hired to do. The authors claim that if this attitude is acknowledged by employers and other decision makers, new possibilities for workers to be self-directed can arise, thus instigating innovation.

At a political level, the challenge of turning automation into innovative activities when the potential for workers' learning is being enhanced through a reshaping of work organisation is underlined by Germany's extension of the discourse on Industry 4.0 to the 4 th generation of work organisation (Work 4.0, see above). Although the supposed link between new forms of automation (notably robots) and a novel work organisation is still rather tenuous (Ahrens \& Gessler, 2018), the overall discussion could have theoretical and practical consequences.

The shaping of enterprises with a view to spurring innovation brings us back to the widespread theoretical assumption that organisational and technological innovations are intertwined (Eriksson-Zetterquist, Kalling et al., 2011). Likewise, Helmrich et al. (2016) state that the introduction of new technology is followed by the issue of workplace rationalisation which calls into question existing structures of power and control. The organisational set-up of manufacturing processes is often implemented in Norway in a non-hierarchical manner (Hertzberg \& Moen, 2010). Scholars subsequently use these characteristics to theorise on the ability of and possibility for employees to influence or even have a lead role in innovation related to a firm's organisation, processes or products. After analysing the responsibilities employees had in five enterprises belonging to a Norwegian network of mechanical enterprises, Hertzberg \& Moen (2010) formulated the following hypothesis:

"The more employees that take part in co-decision making and the more the enterprise is stimulating and rewarding radical or incremental innovations, the more active the employees will be in all kinds of innovative activities of the enterprise" (ibid:30). 
Once more, this evokes the social dimension of workplace design and the training offered at the workplace. S. Pfeiffer (2015) refers to comparisons of the work organisation of manufacturing industries in Germany, Switzerland and Great Britain. One conclusion is that the presence of skilled workers endowed with vocational training at the production level means that the management levels can be leaner than they otherwise would be. The author maintains that Germany exhibits an array of learning requirements, complexity of tasks and problem-solving activities clearly connected to the country's institutionalised vocational training system (ibid.).

In terms of work operations, skills profiles and employment patterns in the wake of automation, Helmrich et al. (2016) conclude that possible job losses can be explained by the occupational blend (Tätigkeitsmix) at the workplace and in specific trades. Particularly important is the relationship between workers and machinery, and the expectations at the workplace relating to the carrying out of tasks at certain cognitive levels (ibid.). In the same paragraph, the authors refute the hypothesis of Frey \& Osborne (2013) that the potential for replacing labour with advanced machinery, as measured by the share of workers carrying out more or less routine work, says much about employment patterns.

\subsection{The impact of robotisation on education and pedagogical perspec- tives}

The impact of robotisation at Osterøy can be observed at three levels. First, the pre-cluster agglomeration is showing an active interest in the ongoing revision of upper secondary VET at the national level. Second, there has been a strengthening of collaboration with the nearest tertiary educational institutions to improve the vocational training offered to employees, apprentices and other learners. Third, cooperation has been initiated with an industrial association in another county of Southern Norway with a view to implementing joint training and skills development in the associations' member firms.

First, the national revision of upper secondary VET will among other things revise the curriculum for the vocational programme Technique and Industrial Production (TIP). This programme is the most relevant one for the island's enterprises. The revised curriculum will be introduced in 2020-2022 following an analysis of how the existing TIP programme aligns with developments in the labour market of manufacturing industries. Much of the process started in 2016 when a tripartite committee presented its conclusions to all stakeholders in the sector. Afterwards, the industrial association at Osterøy has attentively followed the discussions sparked by the committee's report. One major recommendation of the report was to revise the composition of vocational subjects within the TIP programme. Another was to place more emphasis on production techniques compared with industrial machinery mechanics, thereby reflecting sectoral trends towards more focus on production planning for 
efficiency and quality, alongside the reduction of costs due to errors and derogations and the optimisation of all stages of manufacturing. The committee reviewing the TIP programme notably claimed that the curriculum of the second year of 'industrial technology' did not sufficiently mirror the needs expressed by firms working in the sector. Looking into the future, the committee foresaw less need for qualifications in welding and joining techniques. One recommendation of high relevance for the Osterøy Manufacturing Industry Association was to integrate toolmaking in the trade for CNC operators (Utdanningsdirektoratet, 2016).

Second, against the backdrop of the ongoing revision of the TIP programme which is the most popular vocational programme among students at Osterøy upper secondary school, the island's industrial association increasingly focuses on providing vocational training at all educational levels to its member firms. A cooperation agreement with the nearest university college (situated in Bergen) has been used to strengthen and enlarge the number of courses offered to engineers who want to specialise in robotics as part of their training in production technology. While the Osterøy Manufacturing Industry Association has partly succeeded in this, it is worth noting that the university college during these discussions emphasised a wish to broaden the concept of robotisation beyond the industrial sphere by offering training in robotics applied to multiple sectors, including the health and care sector. This emphasis can be interpreted as a strategy to avoid entrenching the university college's robotics training as being only of benefit to manufacturing industries. In a wider perspective, a university college's weighting of robotics across various applications mirrors the position of manufacturing industries within the county's entire industrial and economic framework. As further developed in the following paragraph, this concern has been a point of departure for the industrial association's networking with similar associations. Finally it should be noted that, as well as approaching the university college, the Osterøy Manufacturing Industry Association also contacted the county's vocational technical colleges to ask them develop training courses and programmes in robotics for non-university VET studies.

Third, and to enlarge on cross-county networking, the Osterøy Manufacturing Industry Association concluded in 2017 an agreement with another association (SINTEF Raufoss Manufacturing AS), which is establishing a Manufacturing Technology Norwegian Catapult Centre. The two enterprise agglomerations are situated in two different counties in southern Norway. They share a deliberate strategy of providing systematic training to apprentices, students and employees with a view to supporting a technological renewal of their industries. The agreement envisages workshops and counselling for joint upskilling of firms from both associations alongside joint cooperation projects and staff exchanges. One example of joint firm upskilling mentioned in the cooperation agreement is the common design of the training programmes taught in the catapult centre. It is specified that these programmes should cover vocational education from upper secondary to university level. In sum, the impact of robotisation on education and pedagogical perspectives is most visible when an industrial 
association communicates the training needs of firms to educational institutions and authorities. Our account also suggests that associations sometimes wait for the clarification of external conditions without taking the initiative themselves. When primarily looking at conditions outside the network, industrial associations may take an observational stance that limits their possibilities to identify future training needs for member firms. This limitation partly stems from the variety of manufacturing sectors covered by industrial associations. The presence of loose internal ties in an industrial association points back to our initial discussion of the nature of business networks and how they could be classified. While Osterøy Manufacturing Industry Association (OMIA) seems able to forge a consistent training strategy, it has not shown itself to be very proactive in its relations with national authorities. The Osterøy association can be determined as an extension of its member firms with some limitations in mobilising them to influence the direction of VET. Our interviews suggest that these limitations are primarily rooted in OMIA's small staff and the staff turnover in the local training centre set up by OMIA.

\section{Conclusions}

The literature in the field contains so many contradictory scenarios for job prospects under the present industrial transformation (called Industry 4.0) that the debate now tends to reformulate the key question. Hence, the most fruitful formulation seems to be: which institutional and country-specific characteristics could explain the diverging opinions on the ongoing transformations?

Instead of striking a balance between Industry 4.0 and employment patterns in the USA, Germany and other European countries including Norway, the present article has investigated how some of these processes can be observed at the local level. The relative stable employment pattern that we found in the industrial community under investigation brings us to our first research question:

What are the main drivers behind the local shaping of employment patterns in the network of mechanical engineering firms under scrutiny?

It would be fallacious to draw a clear line between external and internal drivers or mechanisms because, in practice, these mechanisms are intertwined. One general observation is that the Osterøy local network exhibits less cyclical employment variations as a result of simultaneously delivering to two different sectors, the petroleum cluster and non-petroleumbased industries. This seems to ensure more stable employment rates in the agglomeration of enterprises at Osterøy. During preliminary work leading to the present article, one of the key questions formulated was how closely attached specific types of knowledge are to a certain geographical space or, differently phrased, to a cluster-like agglomeration of small mechani- 
cal firms. One preliminary observation is that the recruitment to the island's industries has been facilitated by a "tinker culture of mechanical work" found among young vocational students and workers (Gjelstad, 2015). Future studies of the types of knowledge found on the island should scrutinise the shaping of a local VET culture and the extent to which this culture reflects social characteristics of the local industrial community.

Our second research question was:

How are decisions on profitability, investment in technology and automation, and staff recruitment versus layoffs conciliated or weighted against each other? Are there signs that the social dimension of vocational training is manifested through social responsibility and the emergence of specific training cultures?

In the last instance, such decisions are taken at the level of the firm but the weighting of profitability vs. employment is framed by the local industrial association, partly assisted by the triple-municipality coordination body (Osterfjord Industry Collaboration). The social characteristics of the local training culture is also a determining feature (cf. 'the tinker culture of mechanical work').

The (mutual) trust observed in our case studies could, in principle, be a result of the conciliation processes between organised vocational and occupational interests, in a similar way as the social dialogue in VET is framed across administrative levels in Norway. This dialogue is not, however, very well structured in the investigated enterprises which have a fairly low trade union coverage. The social dimension of VET should therefore also be sought in less institutionalised environments. Following this line of thought, S. Pfeiffer (2015) argues that even where there is no strong workplace representation, it is important to expand codetermination as well as self-determination. This should be done to strengthen the social partnership and "support this with legislation so that it is effective" (ibid.).

The third research question is aimed at elaborating the second one by explicitly linking the balancing of managerial decisions to social aspects of vocational training, including Corporate Social Responsibility (CSR):

Do employers take these concerns into account by implementing a form of CSR that includes responsibility for keeping staff on during robotisation and provides opportunities for further and continuing training?

As suggested by Kaiser \& Krugmann (2018), if different VET actors can create an encouraging climate of mutual trust, it will be easier to develop a social and participatory attitude towards "the new and the foreign" which the rapid automation of mechanical industries does exemplify. This perspective coincides with theories on CSR. On Osterøy, Corporate Social Responsibility is exhibited when the mechanical firms concentrate on product innovation 
and the training of existing staff thus avoiding laying off workers and replacing them with robots during the automation of the island's industry. More specifically, CSR takes the form of a collaboration between enterprises and the local manufacturing association (i.e. a collective expression of individual firms) on the one hand and the municipal and county authorities on the other - in other words a 'stakeholder dialogue' is applied in a specific local context (Carson et al., 2015). The dialogue can be considered a form of voluntary CSR which frames the manner in which technological renewal takes place as well as its rapidity.

Corporate Social Responsibility does, however, have certain limitations in profit-oriented firms. Studies of similar industrial associations in Norway suggest that, above all, attitudes to CSR are conditioned by the length of recessions that the member firms have to tackle. This implies that corporate self-interest is weighted with the common interests within the local community and inside the industrial association, to the extent that the firm's profitability is not at stake (cf. also table 1 on economic sustainability). Applied to enterprise training, similar Norwegian enterprise networks are inclined to keep a kernel of staff during recessions and train these workers until the next economic upswing appears. In general, this allows the firms to compensate for previously postponed staff training to keep abreast with new technical equipment. Such postponements tend to occur during periods of full order books (Teige, 2013; Ure, 2010). Training to avoid lay-offs is normally subsidised by the Public Employment Services. That this is a feature of the CSR in Norway suggests that a closer look at industrial and tripartite relations in pre-cluster agglomerations could be a follow-up of this article.

\section{References}

Aström, K. J. (2004). Introduction to Control. Department of Automatic Control. Lund University: Lund Institute of Technology.

Acemoglu, D., \& Restrepo, P. (2017). Robots and jobs: Evidence from US labor markets. The Quarterly Journal of Economics, 118(4), 1279-1333.

Ahrens, D., \& Gessler, M. (2018). Von der Humanisierung zur Digitalisierung: Entwicklungsetappen betrieblicher Kompetenzentwicklung. In D. Ahrens, \& G. Molzberger (eds.), Kompetenzentwicklung in analogen und digitalisierten Arbeitswelten (pp. 157-172). Heidelberg: Springer.

Alvares, S. A., \& Barney, J. B. (2007). Discovery and Creation: Alternative Theories of Entrepreneurial Action. Strategic Entrepreneurship Journal, 1, 11-26.

Bathelt, H., Malmberg, A., \& Maskell P. (2004). Clusters and knowledge: local buzz, global pipelines and the process of knowledge creation. Progress in Human Geography, 28, 31-56.

Bonin, H., Terry, G., \& Zierahn, U. (2015). Übertragung der Studie von Frey/Osborne (2013) auf Deutschland. Mannheim: Zentrum für Europäische Wirtschaftsforschung (ZEW). Retrieved from http://www.zew.de/de/publikationen/7937

Brynjolfsson, E., \& Mcafee, A. (2014). The second machine age: Work, progress, and prosperity in a time of brilliant technologies. New York, NY: W.W. Norton \& Company. 
Carson, S.G., Kosberg, N.M., Laudal, T., \& Skauge, T. (2015). Etikk for beslutningstakere. Oslo, Norway: Cappelen Damm Akademisk.

Eriksson-Zetterquist, U., Kalling, T., \& Styhre, A. (2011). Organizing Technologies. Malmø, Sweden: Liber.

Fløysand, A., Jakobsen, S.-E., \& Bjarnar, O. (2012). The dynamism of clustering: Interweaving material and discursive processes. Geoforum, 43(5), 948-958.

Frey, C. B., \& Osborne, M. A. (2013). The future of employment: How susceptible are jobs to computerisation. Oxford, UK: Oxford Martin Programme on Technology and Employment.

Gjelstad, L. (2015). Skoleverkstedet som frigjørende handlingsrom: Yrkesfagelevers vilkår for faglig og sosial deltakelse i det post-industrielle Norge. Tidsskrift for velferdsforskning, 18, 18-33.

Gjelstad, L., \& Skauge, T. (2009). Rapport fra Forundersøkelsen om teknologiledelse finansiert av Regionalt næringsfond for Osterforden. Bergen, Norway: University College of Bergen.

Helmrich, R., Tiemann, M., Troltsch, K., Lukowski, F., Neuber-Pohl, C., Lewalder, A. C. (2016). Digitalisierung der Arbeitslandschaften. Bonn: Bundesinstitut für Berufsbildung. Retrieved from https://www.bibb.de/veroeffentlichungen/de/publication/show/8169

Hertzberg, D., \& Moen, S. E. (2010). Deltakende innovasjon: Medarbeideres innovasjonsaktivitet i fem bedrifter i Buskerud. Oslo, Norway: Fafo.

Håkansson, H., Ford, D., Gadde, L.E., Snehota, I., \& Waluszewski, A. (2010). Business in Networks. Chichester, UK: John Wiley \& Sons.

Kaiser, F., \& Krugmann, S. (2018). Social Dimensions and Participation in Vocational Education and Training - An Introduction in the Special Issue. Interntional Journal for Research in Vocational Education and Training, 5(3), 172-177. doi:10.13152/IJRVET.5.3.1

Kock, H., \& Ellström, P.-E. (2011). Formal and integrated strategies for competence development in SMEs. Journal of European Industrial Training 35(1), 71-88.

Lam, A. (2006). Organizational Innovation. In J. Fagerberg, D. C., Mowery, \& R. R. Nelson, The $O X^{-}$ ford Handbook of Innovation (pp. 115-147). Oxford, UK: Oxford University Press.

Laurantsen, R., \& Bergfjord, O. J. (2014). Om økonomisk bærekraft - begrepsavklaring og praktiske eksempler. Unpublished rapport. Bergen, Norway: University College of Bergen, Bergen.

Lindeløv, B., \& Karlsen, A. (2004). Forskning på "Nyskaping i småbedriftsmiljø". Bodø, Norway: Nordlandsforskning.

Marri, H. B., Gunasekaran, A., \& Grieve, R. J. (1998). An investigation into the implementation of computer integrated manufacturing in small and medium enterprises. The International Journal of Advanced Manufacturing Technology, 14(12), 935-942.

Marshall, A. (1890). The principles of economics. London: Macmillan. Retrieved from https://archive. org/stream/principlesecono00marsgoog\#page/n8/mode/2up.

Martin, L. M., \& Beach, K. (1992). Technical and symbolic knowledge in CNC machining: A study of technical workers of different backgrounds. Berkeley, CA: National Center for Research in Vocational Education.

Njøs, R., \& Jakobsen, S.-E. (2016). Cluster policy and regional development: scale, scope and renewal. Regional Studies, Regional Science, 3(1), 146-169.

Peng, M. W., Sun, S. L., Pinkham, B., \& Chen, H. (2009). The institution-based view as a third leg for a strategy tripod. Academy of Management, 23(3), 63 - 81.

Pfeiffer, S. (2015). Effects of Industry 4.0 on vocational education and training. Vienna: Institute of Technology Assessment. Retrieved from http://epub.oeaw.ac.at/ita/ita-manuscript/ita_15_04.pdf 
Porter, M. E. (1980). Competitive strategy: Techniques for analyzing industries and competitors. New York, NY: The Free Press.

Porter, M. E., \& Heppelmann, J. E. (2014). How smart, connected products are transforming competition. Harvard Business Review, 92(11), 64-88.

Price, O.M., Boud D., \& Scheeres H. (2012). Creating Work: Employee-driven innovation through work practice reconstruction. In S. Høyrup, M. Bonnafous-Boucher, C. Hasse, M. Lotz, \& K. Møller (eds.), Employee-driven innovation: a new approach (pp. 77-91). Palgrave: Macmillan.

Reve, T., \& Sasson, A. (2012). Et kunnskapsbasert Norge. Oslo, Norway: Universitetsforlaget.

Rus, D. (2015). The robots are coming: How technological breakthroughs will transform everyday life. Foreign Affairs, 94(4), 2-7.

Schwab, K. (2016). The fourth industrial revolution. Davos: World Economic Forum.

Skjærvik, K. R. (2014). Innføring av CNC og robotteknologi - teknologiledelse i små og mellomstore bedrifter. University of Oslo: Centre for Entrepreneurship.

Teige, B. K (2013). Campus Ålesund: Maritime Møre sin rolle i utviklingen av et kraftsenter for kompetanse. Oslo/Tromsø: Norgesuniversitetets skriftserie.

Ure, O. B., \& Skauge, T. (2014). Literature for studies of upskilling and technology management in clusters of SME: A review. University College of Bergen.

Ure, O. B. (2010). Formal education in an informal Norwegian culture of enterprise training. Six cases collected from maritime and offshore environments. National report from subproject 4 in the frame of the EU 6th Framework programme project 'Lifelong Learning 2010'. Oslo: Fafo.

Utdanningsdirektoratet (2016). Gjennomgang av det yrkesfaglige utdanningstilbudet: Utdanningsdirektoratets anbefalinger til Kunnskapsdepartementet. Oslo: Utdanningsdirektoratet.

\section{Biographical Notes}

Odd Bjørn Ure, cand. polit. from the University of Bergen (Norway), is independent researcher and consultant in his own firm, Consultur. Studies\&Analyses (www.consultur.no). His main research interests are links between enterprises and the labour market, in terms of vocational training and other forms of education.

Dr polit. Tom Skauge, from the University of Bergen (Norway), is Head of Department at the Western Norway University of Applied Sciences, Department of Business Administration. His main research interests are ethical aspects of professional practice, corporate social responsibility and regional development.

\section{Acknowledgements}

Several persons from or trained at the Western Norway University of Applied Sciences (HVL) have contributed to the article or to the empirical material on which it builds, particularly: Ole Jacob Bergfjord, Åge Garnes, Roald Laurantsen, Hanne S. Sjøvold and Kjerstin R. Skjærvik. Towards the end of the writing, the comments from Professor Age Garnes were very helpful. 